\title{
Evaluating the effect of price and non-price policy intervention on rice cultivation in Sierra Leone: $A$ supply response model approach
}

\author{
Alhaji Mohamed Hamza Conteh ${ }^{*}$, Xiangbin Yan \\ Management Science and Engineering, School of Management, Harbin Institute of Technology, Harbin, China; \\ *Corresponding Author: hadjmannc90@yahoo.com
}

Received 30 October 2013; revised 14 December 2013; accepted 25 December 2013

Copyright (C) 2014 Alhaji Mohamed Hamza Conteh, Xiangbin Yan. This is an open access article distributed under the Creative Commons Attribution License, which permits unrestricted use, distribution, and reproduction in any medium, provided the original work is properly cited. In accordance of the Creative Commons Attribution License all Copyrights (C) 2014 are reserved for SCIRP and the owner of the intellectual property Alhaji Mohamed Hamza Conteh, Xiangbin Yan. All Copyright (C) 2014 are guarded by law and by SCIRP as a guardian.

\section{ABSTRACT}

Rice is the main food for over 95 percent of the Sierra Leonean populace. It accounts for the largest portion of the agricultural GDP of the country. On the contrary, its cultivation has been shrinking over the past decades. Consequently, importation now becomes the main source of supplying the grain for local needs since its cultivation or production could no longer meet domestic request. The deterioration in the local cultivation of rice has had severe socio-economic implications such as higher consumer prices and balance of payment burden. Therefore, the main objective of this study is to evaluate the effect of price and other related nonprice policy intervention on rice cultivation in the country. The tools utilized for analyzing the problem comprise, a coefficient of protection analysis as well as a supply response analysis by means of a time series regression (for the period 19802011). Major limitations established negatively affecting rice output are price disincentives to cultivators, public expenditure and fertilizer consumption. From the above findings, rice cultivators should be accorded the necessary incentives to keep them more effective in the rice cultivation career. The food policy approach that had over the years depended on huge importation of rice should be reviewed in favor of domestic cultivation. Increasing local cultivation through a meaningful protection of cultivators can independently reduce the price of rice to the advantage of the final consumers. This study also recommends that public funds should be redirected away from rice import toward investments in its domestic cultivation.

\section{KEYWORDS}

Rice; Imports; Cultivation; Cultivators; Price; Policy Interventions; Supply Response Model

\section{INTRODUCTION}

Rice is developing as a staple food crop in Africa [1], where it is grown in around 46 countries [1]. In recent times, rice has become a staple food for both urban and rural consumers [2] throughout West African countries including Sierra Leone. Yet, the West African region has observed a sharp drop in rice cultivation within the last two decades. However, attempts are ongoing to reverse that trend by drastically increasing food supplies. Western Africa countries had experienced sluggish growth in their agricultural sectors [3]. Rice cultivation has been increasing more rapidly than population in many parts of the globe, but Africa has been lagging behind. This difference between cultivation and population growth in Africa is creating harmful results including external debt.

The barriers that appear to distress agricultural efficiency in Africa are inadequate irrigation, drought, diseases, pests, limited fertilizer consumption, civil conflicts and unfitting national policies. In addition to other economies, rice grain takes a central position in the economy of Sierra Leone and its level of cultivation has both political and socio-economic implications. The country was once a giant exporter of rice grain during certain eras. Yet, this was not continued, and its rice sta- 
tus had changed from beeing an exporter to an importer [4].

Rice is the leading staple food in Sierra Leon. Though the country has a vast arable land area to cultivate the crop with almost every farmer vigorously involving in cultivating it, not all its citizens in the country are getting sufficient of it. Efforts of the present and past governments along with their respective partners over several years in investing in the agricultural sector in an attempt to make the nation rice self-sufficient are so far not realized. In order to meet the essential responsibility of feeding its people and to even avoid social and political unrests, the government has to spend huge foreign exchange that would have been otherwise used to meet other pressing developmental needs to import rice into the country. The yield gap in rice production in Sierra Leone is not only huge but costly and therefore of serious national concern. The average yield generally obtained in Sierra Leone is about 1.43 metric ton/hectare and is sadly very low, and it is even worse in the upland ecologies where most of the farmers cultivate rice. Some of the alleged constraints facing the rice cultivators in Sierra Leone include the use of low yielding traditional varieties, low quality of seeds, pest and disease factors, nutrient imbalances, poor water management, high postharvest losses and lack of credit facilities.

Rice cultivation has been decreasing over the last two decades. The population and demand for the crop have been on the increase as the total cultivated area to the crop presents negative tendency.

The resultant food scarcities had led to an increase in rice importation and therefore, have exhausted the country's foreign reserve. It is against this background that the authors attempt to find out the root cause of the wide yield gap in rice cultivation in Sierra Leone, thereby evaluating the effect of price and non-price policy intervention on rice cultivation in Sierra Leone.

Policies interventions that are implemented by many African states had possessed their share of responsibility for the deprived condition of the agricultural sector in the region. There is a strong believe that for agriculture to develop, cultivators should receive price incentives and policy makers in Africa should create reserves that will harmonize private enterprises initiatives. Some countries in Africa are accounted to have noticed unfortunate policy formations upsetting agricultural activities. The overvalued United States dollar led to depressed prices and lower farm profits [5], causing an undervaluation of farm resources. Also, higher exchange rate and strict exchange controls that are connected with weak financial systems, distorted foreign exchange markets [6], and urban wage rates are also unlikely to increase food prices and hence impede agricultural growth. Most of the structural adjustment policies that have been put into practice in most African countries have failed to account with much achievement in improving growth crisis in the continent. Global policies pursued are alleged to have accelerated the poor performance of agricultural sector in Africa. As Gugerty et al. [7] cited Sahrawat et al. [8] that, global trade distortions are still damaging the cultivators in developing countries and that the global rice market is highly distorted caused by heavy support provided by developed nations. The uncertain international debt problems are a serious restraint confronting agricultural activities in Africa. Substitute soil fertility in agriculture is an additional concern regarding fertilizer acquisition, its appropriate organizations, farming systems and land use techniques. The role of highly graded fertilizers appears to be a central key in achieving agricultural requirements, but it has been deterred by several factors replicated in the low rate of fertilizer application in Africa. Labor intensively depends more on domestic materials, low level technologies and regulatory frameworks that support economic growth, infrastructural improvement and capacity building have been probably without a substantial assortment of input. The industrious capacity of these inputs is apparently very low. Most developed countries are able to produce fertilizers for their agricultural use, but in Africa, only Nigeria is talented in producing fertilizer locally. The minimal fertilizer consumption is caused by the limited flow of money encountered by cultivators due to poor price incentive and inadequate foreign trade aggravated by deflation policies. Thus, this limits the import of fertilizer.

In developing countries, rice cultivation efficiently utilizes scarce local resources and its expansion is socially appreciated. Other policy indicators such as the nominal protection coefficient (NPC) and the effective protection coefficient (EPC) show varied public support levels. However, the authors would like to emphasize on the NPC. The NPC is a ratio that contrasts the observed (private) commodity price with a similar global (social) price, or simply, the NPC for a given commodity is the ratio of its domestic price to its global price. With the help of NPC, Sowa et al. [9] examined farming incentive organizations in 18 developing nations for two phases (1975-1979 and 1980-1984). They started that, amongst the 18 countries examined, it was just Chile for the first phase and Portugal for both phases could accord positive incentives to their cultivators of chosen export products such as rice through direct and indirect pricing policy interventions in agriculture. The other countries examined accorded their cultivators with negative incentives and this virtually depressed them from cultivating more crops. The deterrent impact of the indirect policy (market wide policies for instance exchange rates) was established to lead the direct policy interventions. Consequently, letting market forces resolve the course of agri- 
cultural pricing was suggested. Sowa et al. [9] stated that the lack of debt about the implications of macroeconomic policy for agricultural activities as a strong contributing factor for producers increases disincentives. A research carried out on adjustment schemes and agricultural inducements for Sudan by Toure et al. [10] arrived at the same end as the later using protection coefficient analysis (PCA). To buttress more on agricultural impasse, the authors have explored into agricultural supply response estimation. The aggregate and single cropwise, estimated supply elasticity to dig further into the factors that influence the rice cultivation. The uninteresting observation upheld by many regarding the established ideas of the World Bank and IMF that "once prices are right" cultivator's will double their output has been strongly criticized in African economies. Reaching the essential price incentives for increase agricultural efficiency is a main factor to consider, but there are many other problems affecting agriculture in Africa that require appropriate attention. As reported by Jing Zhong et al. [11], Zhang et al. [12] employed a cross-country analysis to argue for an increase in cultivator prices to motivate agricultural supply and they anchored in a more than-one elasticity of supply estimates. Conversely, Miheretu et al. [13] criticized Zhang et al. [12] on such conclusion. In fact, Miheretu et al. [13] listed factors such as land limitations, accessibility of credits, environmental traits, and official status of production. They opined that these factors cannot be eliminated basically by escalating prices. On including these factors in agricultural supply estimation, Miheretu et al. [13] brought the price elasticity estimates below one (against Zhang [12]) using the same model for some developing nations with related organizations.

Also, Reardon et al. [14] evaluating the role of price and non-price factors in agricultural supply confined in their model the result of agro climatic prospects, human assets, physical infrastructure, extension services, irrigation, rural populace, research and imports. They established that the non-price factors reported the majority of the variations in supply; the nation's specific time series individual price elasticity estimate they achieved was below one supporting Miheretu [13]. It appears to be an agreement amongst authors that non-price factors are the key barriers that discourage growth in agricultural output in many African economies. Structural adjustment programs (SAP) followed under the confidence "making the price corrects" may perhaps not submit the required results in agriculture for most developing nations.

\section{Price and Nonprice Policies in Sierra Leone}

Price policy analysis has been established as a key in agricultural production research in Sierra Leone where price has been a basic factor in influencing farm production. Cultivators increase their output in response to price as well as nonprice factors. The general nonprice factors classically used in empirical analysis above include, public investment in research, irrigation, rice importation and land; different theories have been developed to explain the changes of supply in agriculture. Theoretically, with respect to the neoclassical economic viewpoint concerning optimization performance of the farm, price appears as the key pertinent issue that manipulates production at all levels, [as everything being equal] as increase in price level of production will definitely increases proceeds to factors of production, thus, giving cultivators incentives to utilize additional input and consequently, increase production. As for different products, a relatively small change in price level results in a shift in production from a single output to the other through resource redistribution as modification is made in reaction to changing comparative profitability of different outputs. However, the later could clarify why cross border events at times occur such as smuggling in a situation where a decrease in producer prices compared with those in neighbouring states stimulates domestic movement of resources among crops and sometimes the movement will be from staple to cash crop, thus, taking advantage of price incentives in nearby states. To realize farm production, price policy goal is an opposing point from political to socio-economic views. As noted by Ellis [15], these objectives include: to influence agricultural production, to attain the needed changes in income distribution and lastly, to influence the role and involvement of the agricultural sector to the general process of economic growth. However, the above objectives sometimes result in disagreement. To achieve the necessary changes in income allocation through, for instance, reducing food prices and increase income level of the nonfarm rural and urban deprived against increasing farm production is imperative.

Achieving economic growth might stimulate support for policies that will definitely help industrialization besides agricultural activities. Generalization of this range of policy complication is mostly an issue of main concern and direction of specific objectives in the interest of the general public.

\section{DATA SOURCE AND MODEL SPECIFICATION}

\subsection{Data Sources}

Data on output, cultivated area, public investment, fertilizer consumption, imports and producer prices of rice crop during the past years were collected from the Food and Agricultural Organization database (FAOSTAT, 2012). Others were collected from government agencies 
in Sierra Leone such as the Ministry of Agriculture, Forestry and Food security, the Sierra Leone Agricultural Research Institute (SLARI) and Statistics Sierra Leone (SSL). Furthermore, the study sourced information from published papers in reputable journals. The data set covers form 1980-2011 period.

\subsection{Model Specification}

\subsubsection{Coefficients of Protection Analysis}

This is a method use to explore the incentive structures that are essential for price policy interventions. For this study, the instrument is use in the context of policies that are affecting rice cultivation or output and to find out whether rice cultivators in Sierra Leone are accorded with incentives.

There is a range of coefficient measures that are used in the literature for such assessment that compare local and border prices. Although the archival data is difficult to access, an easy, but widely used coefficient of protection is utilize in this research and that is the Nominal Protection Coefficients (NPC). However, other researchers that have employed this instrument in evaluating cultivators incentives are [10,16-18]. The coefficient can be mathematically represented as:

$$
N P C_{\text {it }}=\frac{\text { domestic price }}{\text { border price } \times \text { exchange rate }}
$$

where

$$
N P C_{\mathrm{it}}=\frac{p_{i}^{d}}{p_{i}^{b}}
$$

$P_{i}^{d}=$ domestic price of the $i^{\text {th }}$ commodity; $\mathrm{t}$ is the time, $P_{i}^{b}=$ Border price of the $i^{\text {th }}$ commodity United States products price is use as proxy for the foreign price, which is converted into local currency to achieve the border price using an appropriate exchange rate. NPC then becomes real protection coefficient identify as the nominal rate of protection (NRP), which can be represented as:

$$
N R P=\frac{P_{i}^{d}-P_{i}^{b}}{P_{i}^{b}}=N P C-1
$$

Rice cultivators are protected or accorded with incentives if

$$
N P C \succ 1
$$

getting better prices at the expense of the final consumers than would be the situation where there is nonexistence of policy intervention and this is also true for the reverse. If the policy creates unbiased effect on cultivators and consumers (in the absence of both subsidy and tax) then,

$$
N P C=1
$$

However, because of data collection difficulties, par- ticularly on local inputs, the authors are limited to the use of NPCs. And this is one of the generally limitations of protection coefficients analysis, that, its might not be clear from estimates regarding which type of policy constituent has caused incentives or disincentives. The results of the NPCs will establish whether rice cultivators are accorded with price incentives or not.

\subsubsection{Supply Response Analysis}

Supply response analysis has long been a matter of interest in agricultural economics [19]. Lately, some researchers have evaluated the effect of price uncertainty using supply response analysis. Theoretically, it is broadly established that supply response elasticities are usually higher for particular crops than aggregate. As individual crops theoretically react to price factors by a significant level, aggregate supply response is thought to be low. This is because a crop's cultivation response can be augmented in the short run by simply shifting resources from others in the direction of its production. This is not the case with the general sector response as the main factors of production (land, labour and capital) are fixed; shifting resources in support of one crop means neglecting the production response of the others so that all crops responses become unworkable. It is in the long run that the feasibility exists for aggregate output to respond as well as individual crops, since fixed factors would become adjustable and variable; as more resources are devoted to agriculture, or if technology changes; or if there is an investment in infrastructure such as, roads, market, irrigation, education and health. It is in similar judgment that individual crop supply elasticity is estimated to be higher in the long run than in the short run. The estimation of a crop response can be in terms of area, yield, output or production.

\subsubsection{The Regression Model}

Time series regression model is adopted and anchored in ad hoc specifications within the structure of the Nerlovian supply response model that were widely used in the literature. This particular model is borrowed from [20] and [21]. Nerlovian approach is chosen, which is based on price expectations [22] and its supply response method has some limitations; which is the extreme reliant on price factor as the main determinant of production response. As observed by Jing Zhong et al. [11] that, because of the structures of the Sierra Leone economy, like any other poor nation, the model is modified to incorporate non-price factors seen most influential on output supply. The functioning model can be express as:

$$
\begin{aligned}
(\text { QDRC })_{t}= & \beta_{1}+\beta_{2}(\text { QDRC })_{t-1}+\beta_{3}(\text { PPRICE })_{t} \\
& +\beta_{4}(P I)_{t}+\beta_{5}(\text { AURC })_{t}+\beta_{6}(\text { QIR })_{t} \\
& +\beta_{7}(F C)_{t}+\beta_{8}(D U V)+\varepsilon_{t}
\end{aligned}
$$


where $Q D R C=$ quantity of domestic rice cultivated or output, $t=$ is the current year, $\mathrm{t}_{-1}=$ is the previous year, PPRICE = producer's price of rice, $\mathrm{PI}=$ public investment, $A U R C=$ area under rice cultivation, $Q I R=$ is the quantity of rice imported, $F C=$ fertilizer consumption, $D U V=$ dummy variable for the civil conflict in Sierra Leone, $\varepsilon=$ error term, is assume to have zero expected value, $\beta_{i}=$ a vector of the parameters.

$(Q R P)_{t-1}$ is the previous year's production level (creating an autoregressive model) the coefficient of which enables us to decide the rate at which actual production adjusts to the preferred cultivation or production. PPRICE is the ratio of producer price of rice to consumer price index and it is expected to have a positive impact on rice cultivators. A short fall in producer price relative to retail price index (reflecting the effect of inflation) is expected to discourage cultivators; the reverse will also be true. PI is public investment; it is use as a proxy of social amenities and/or research costs. In the Sierra Leone situation, the PI coefficient cannot be signed with certainty. Where the preferred impact of public expenses is felt by rice cultivators in terms of feeder roads construction, provision of social amenities in the poor communities, and ensuring that agricultural programs reach the cultivators, then, PI will be expected to influence rice output positively; but where the opposite is the situation, (i.e. public venture will just be restricted to the provision of roads and social infrastructures for the bigger cities), then, one will certainly expect PI to adversely affect rice output; the negative impact will result where unequal public infrastructural venture in the bigger cities serves as a strong opinion for the attraction of rural labour. AURC is area under rice cultivation and it is expected to have a positive impact on rice production. Quantity of rice imported (QIR), is expected to affect local rice output negatively. There is an assumption that, the higher the quality of imported rice together with subsidization of its price by state and its easiness in cooking; the lower the demand for the local rice and hence, a reduction in its cultivation. The variable FC is the quantity of fertilizer consumption and it is expected to have a positive effect on rice output. DUV is a dummy variable for the effect of the civil conflict in Sierra Leone. The model is estimated in log form to enable us understand the results as elasticities.

\subsubsection{The Model Estimation Methods}

The estimated model is an autoregressive distributed lag (ADL) in which the OLS method is used. In an attempt to capture the dynamic behaviour of rice cultivation in Sierra Leone, the model is estimated in several ways using different lag lengths to reach at a plausible estimate. The Eviews software is use for the estimation. Various econometric tests are carried out to ascertain the reliability of estimates.

\section{RESULTS AND DISCUSSION}

\subsection{Results of the Nominal Protection Coefficient}

From the estimated nominal protection coefficients $(N P C)$, in Table 1, it appears that rice cultivators were

Table 1. The Nominal Protection Coefficients (NPC).

\begin{tabular}{|c|c|c|c|c|}
\hline YEAR & DOMESTIC & BORDER & NPC & NRP \\
\hline 1980 & 140 & 82.40 & 1.70 & 0.70 \\
\hline 1981 & 143 & 83.20 & 1.72 & 0.72 \\
\hline 1982 & 146 & 84.30 & 1.73 & 0.73 \\
\hline 1983 & 146 & 95.48 & 1.53 & 0.53 \\
\hline 1984 & 146 & 99.63 & 1.47 & 0.47 \\
\hline 1985 & 167 & 102.95 & 1.62 & 0.62 \\
\hline 1986 & 135 & 123.50 & 1.09 & 0.09 \\
\hline 1987 & 104 & 254.29 & 0.41 & -0.59 \\
\hline 1988 & 130 & 217.43 & 0.60 & -0.40 \\
\hline 1989 & 267 & 170.71 & 1.56 & 0.56 \\
\hline 1990 & 267 & 177.06 & 1.51 & 0.51 \\
\hline 1991 & 293 & 245.36 & 1.19 & 0.19 \\
\hline 1992 & 253 & 194.10 & 1.30 & 0.30 \\
\hline 1993 & 398 & 249.87 & 1.59 & 0.59 \\
\hline 1994 & 361 & 301.20 & 1.20 & 0.20 \\
\hline 1995 & 437 & 237.10 & 1.84 & 0.84 \\
\hline 1996 & 520 & 220.77 & 2.36 & 1.36 \\
\hline 1997 & 629 & 362.22 & 1.74 & 0.74 \\
\hline 1998 & 935 & 449.28 & 2.08 & 1.08 \\
\hline 1999 & 1105 & 737.97 & 1.50 & 0.50 \\
\hline 2000 & 1305 & 1340.48 & 0.97 & -0.03 \\
\hline 2001 & 2785 & 5451.50 & 0.51 & -0.49 \\
\hline 2002 & 7405 & 4914.02 & 1.51 & 0.51 \\
\hline 2003 & 22205 & 9694.23 & 2.29 & 1.29 \\
\hline 2004 & 29045 & 22268.16 & 1.30 & 0.30 \\
\hline 2005 & 37045 & 49326.79 & 0.75 & -0.25 \\
\hline 2006 & 44405 & 64932.30 & 0.68 & -0.32 \\
\hline 2007 & 48005 & 99877.97 & 0.48 & -0.52 \\
\hline 2008 & 50005 & 86842.53 & 0.58 & -0.42 \\
\hline 2009 & 60005 & 120840.30 & 0.50 & -0.50 \\
\hline 2010 & 70005 & 144400.10 & 0.48 & -0.52 \\
\hline \multirow[t]{2}{*}{2011} & 80005 & 150000.10 & 0.53 & -0.47 \\
\hline & & AVERAGE & 1.2604 & 0.2604 \\
\hline
\end{tabular}


been accorded with incentives generally. The average NPC within the period 1980-2011 shows an incentive of about 26 percent being accorded to cultivators of the grain as a result of policy intervention. This seems unclear since rice cultivation or output has been declining gravely in Sierra Leone. Conversely, accounting for the exchange rates distortion, the nominal rate of protection (NRP), which is the correction of NPC to reflect accurate resource use, confirms disincentives to cultivators of the crop of about 26 percent. Anchored in this latter measure deemed more effective, thus, one could conclude that policy interventions into the markets accorded cultivators negative incentives and this may have partially contributed to the actual decline in rice cultivation or output over the years.

Figures 1-4 show the domestic price, border price, NPC and NRP concerning rice. It explains that the border price has been actually increasing at a price higher than the domestic price of rice. This can be seen in the trend equations (Figures 1 and 2) leaving the NPC as well as

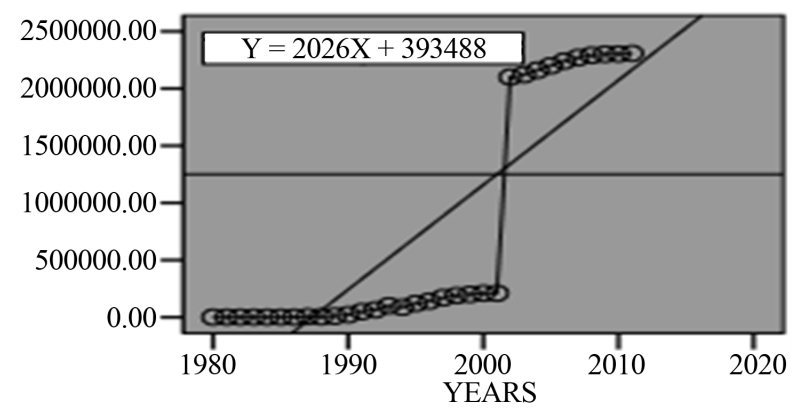

Figure 1. Domestic price of rice (Le).

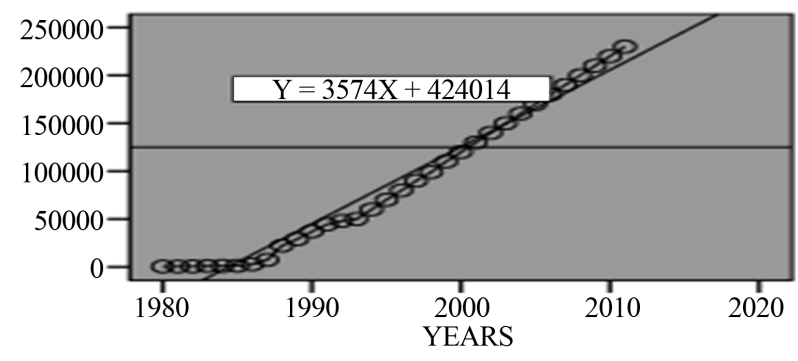

Figure 2. Border price of rice (Le).

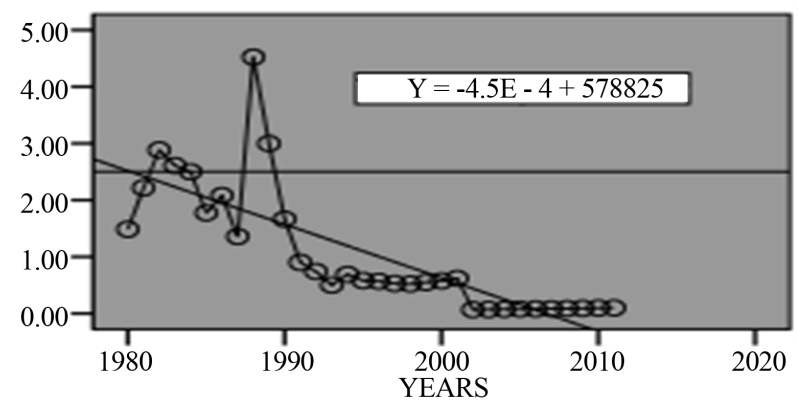

Figure 3. The Nominal Protection Coefficient (NPC).

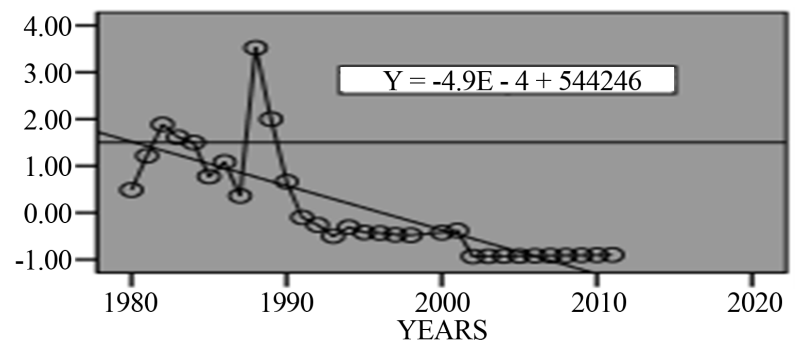

Figure 4. The Effective Nominal Rate of Protection (NRP).

NRP with negative trends as shown in Figures 3 and 4. This verifies a reduction in rice cultivators' incentives over the period 1980-2011. This results should thus, be interpreted with caution as such protection measure only considers one side of cultivators' crop activities and that is the revenue aspect, it fails to capture the cost aspect that will enable us understand better the incentive structure in terms of cultivators' profitability.

\subsection{Regression Results}

The results are ADL model output using OLS technique, where each variable is lagged thrice in an attempt to capture the dynamic behavior of rice cultivation in Sierra Leone. The Eviews software package was used for the estimation.

From Table 2, the rice output in Sierra Leone responds positively to last year as well as the year before prices and each is significant at $10 \%$, although with a very low elasticities (0.02 and 0.17 respectively). This implies a $10 \%$ increase in last year as well as the year before producer prices compare with consumer price index brings about a $0.2 \%$ and $1.7 \%$ increase in output respectively. The low price elasticities for the Sierra Leone situation are not surprising since the country is one of the poorest nation whose cultivators' response to price is discourage by many structural rigidities that include poor infrastructural network as well as flawed institutions. The current year price with its third lag is not actually significant.

All Public investment variables such as current and lagged are found insignificant in affecting rice output in Sierra Leone. This may not be doubtful for a nation where public expenditure is not appropriately directed. The expenditure on agriculture could be great, but if this is just limited to setting up office buildings, spending on unskilled employees, employing agricultural experts etc, it will not be easy to realize the expected goals of the financial plan. Without reaching the constraint of the cultivators through provision of the necessary farm implements, rural amenities, fertilizers, effective extension service, better feeder roads, etc, a key aspect of the public expenditure towards agriculture could only results to waste of resources. Thus, this would not have the expected impact on rice cultivation. All lagged QIR va- 
Table 2. The General Model of Rice Output (QDRC) 1980-2011.

\begin{tabular}{|c|c|c|c|c|c|}
\hline Variable & Coefficient & Std. Error & t-value & t-prob & partial $r^{2}$ \\
\hline Constant & 20.314 & 8.2040 & 2.091 & $0.0972^{* * *}$ & 0.7100 \\
\hline LQDRC_1 & -0.90081 & 0.40110 & -2.862 & $0.0655^{* * *}$ & 0.7601 \\
\hline LQDRC_2 & -0.29872 & 0.30561 & -0.971 & 0.4171 & 0.2345 \\
\hline LQDRC_3 & -0.42813 & 0.30622 & -1.521 & 0.3761 & 0.4667 \\
\hline LPRICE & 0.08771 & 0.07212 & 1.685 & 0.3127 & 0.7526 \\
\hline LPRICE_1 & 0.03272 & 0.06311 & 0.161 & $0.0917^{* * *}$ & 0.0169 \\
\hline LPRICE_2 & 0.22127 & 0.07123 & 2.656 & $0.0991^{* * *}$ & 0.8716 \\
\hline LPRICE_3 & -0.13113 & 0.10344 & -1.241 & 0.3109 & 0.6116 \\
\hline LPI & 0.02411 & 0.03132 & 0.972 & 0.5631 & 0.3871 \\
\hline LPI_1 & 0.01312 & 0.06126 & 0.416 & 0.8235 & 0.0541 \\
\hline LPI_2 & 0.12516 & 0.08132 & 1.819 & 0.2553 & 0.5671 \\
\hline LPI_3 & -0.05121 & 0.06503 & -1.233 & 0.4561 & 0.5610 \\
\hline LAURC & -0.52264 & 0.56143 & -1.246 & 0.3549 & 0.6056 \\
\hline LAURC_1 & 0.51174 & 0.26084 & 2.414 & 0.6161 & 0.7118 \\
\hline LAURC_2 & 0.25561 & 0.41431 & 0.891 & 0.5841 & 0.2171 \\
\hline LAURC_3 & 0.72185 & 0.38181 & 2.362 & $0.0088^{*}$ & 0.6536 \\
\hline LQIR & -0.01609 & 0.03301 & -1.113 & 0.5015 & 0.3405 \\
\hline LQIR_1 & -0.03115 & 0.01140 & -2.306 & $0.0168^{*}$ & 0.7168 \\
\hline LQIR_2 & -0.05504 & 0.02403 & -3.402 & $0.0688^{* *}$ & 0.8100 \\
\hline LQIR_3 & -0.05069 & 0.02679 & -3.608 & $0.0516^{* *}$ & 0.9032 \\
\hline LFC & 0.04610 & 0.06124 & 0.932 & 0.5261 & 0.2024 \\
\hline LFC_1 & 0.15350 & 0.20632 & 0.799 & 0.4450 & 0.2353 \\
\hline LFC_2 & -0.08693 & 0.11001 & -1.203 & 0.5111 & 0.3081 \\
\hline LFC_3 & 0.61264 & 0.30211 & 2.413 & 0.1225 & 0.8390 \\
\hline DUV & -0.31450 & 0.17120 & -1.618 & $0.0219^{* *}$ & 0.5415 \\
\hline \multicolumn{6}{|c|}{$\mathrm{R}^{2}=0.991842, \mathrm{~F}(28,3)=17.001[0.0196] \mathrm{DW}=2.431$} \\
\hline \multicolumn{6}{|c|}{ Short-run price elasticity $=0.010$} \\
\hline \multicolumn{6}{|c|}{ Long-run price elasticity $=0.006$} \\
\hline \multicolumn{6}{|c|}{ Diagnostic Test } \\
\hline \multicolumn{6}{|c|}{$\begin{array}{l}\text { AR } 1-1 \mathrm{~F}(1,2)=0.96103[0.4427], \mathrm{SC}=-4.48, \\
\text { ARCH } 1 \mathrm{~F}(1,8)=0.0019185[0.9588] \\
\text { Normality Chi^ } 2(2)=0.87451[0.6549] \\
\text { RESET F }(1,2)=0.000737[0.9729]\end{array}$} \\
\hline
\end{tabular}

SC = Schwarz information criterion; ${ }^{*}$ Significant at 1\%, 5\% \& 10\%; ${ }^{* *}$ significant at 5\% \& 10\%; ${ }^{* * *} 10 \%$. Ln = natural logarithm; QDRC = Quantity of rice cultivated domestic output (dependent variable); PPRICE = Producer price of rice; PI = Public investment; AURC = Area under rice cultivation; QIR = Quantity of imported rice; FC=Fertilizer consumption; DUV = Dummy variable for the civil war in Sierra Leone. 
riables significantly and negatively affect rice output in Sierra Leone, although with a very low elasticity response. This low negative response might be due to the reality that the full negative multiplier effect of imports is partially offset by the positive effect it produces, since during the cultivation process, cultivators would require food for work which comes mostly from imported rice grain from the markets and such food for work will make them work harder and increase local cultivation of the grain. Thus, given the higher quality of the imported rice grain, its subsidized price, and possibly ease of cooking, domestic grain is frequently packed out of the market, hence the reason for the negative net impact proposed in this study. The current QIR variable has the expected sign although it is insignificant, suggesting rice importation really affects domestic cultivation of the grain with a lag.

For the area under rice cultivation, both current acreage expansion and that of the last two years fail to have significant effects on the current rice output. However, its increase three years ago (AURC_3) shows with a positive with significant effect. This insignificant rice response to current and the last two years increase in acreages may result from the reality that area cultivated may have increased, although if there were not improved rice cultivars or adequate use of fertilizers the cultivation would not be significant; particularly with upland agricultural systems with low natural nutrients. The crop yield might have only responded significantly to increased acreage after a substantial time lapse when complementing factors as those mentioned are obtained. However, under no circumstances that current or lag has fertilizer consumption (FC) showed significant in affecting rice cultivation (Table 2). This may not also be astonishing since fertilizer is very expensive. Considering the low-income level of most cultivators in the country as reflected in the dominance of small-scale agriculture, the use of fertilizer on farm lands would be on a very smaller-scale, while the costs of inputs are on the increase with increase in foreign exchange rate levels. Ogunlade et al. [23] studied the evaluation of the level of fertilizer utilization for cocoa cultivation in Nigeria also found insignificant result for fertilizer use partly as a result of the reason given above and because the input was been obtained by cultivators in that country from the local or black market. The dummy variable which captures the impact of the civil conflict comes out significantly with the expected negative effect on rice cultivation.

$\mathrm{R}^{2}$ and F-test statistics demonstrate significant goodness of fit of the regression model. According to the diagnostic tests, there is no problem with the test of normality of the error term. The model is well specified with no problem of heteroscedasticity and absence of serial correlation is affirmed. Any incidence of nonstationarity can be minimize by the inclusion of several lagged variables in the model.

\section{CONCLUSIONS}

The above analyses confirm that low producer prices create disincentives to rice cultivators and consequently, a decline in rice cultivation in Sierra Leone. A decrease in producer price in relation to the consumer price index sets to have a descending pressure on cultivators' purchasing ability, which would ultimately discourage rice cultivation as farm labour period might be shortened towards off-farm employment to supplement incomes. Nevertheless, considering the least response of rice output to prices as replicated in the regression results, higher prices that cultivators receive would not appear to be the solution of the food's scarcity. There appears to be strong determinants (the non-price factors) that influence rice output response to price, also this suggests among other things of depressed infrastructural base, limited and poor road networks to connect farming zones and to main market centres and unreachable credit facilities supported by non-integration of formal credit organizations especially into the farming areas. With exchange rate increasing as it has been, many cultivators might have gone without any use of the inputs as its resulting domestic cost would be irrational to many cultivators.

Importation of rice was discovered negatively and significantly affecting domestic cultivation. The economic strategy of extreme dependence on rice imports to decrease the food gap in Sierra Leone is seen by this study as a mischievous policy approach.

Excessive rice imports when foreign exchange reserves are at their lowest level would simply lead the country to more financial crises since acquiring huge external debt in this case is unavoidable for which both the private and public funds will be constricted toward its servicing, consequently, suppressing domestic investment activities which embrace rice developmental plans. Rice importation policy may prosper in the short-run, but might deteriorate an already severe food insufficiency situation in the medium and long-tern. For lack of sufficient data, this study cannot establish whether it is on efficiency view in terms of cost of domestic rice cultivation outweighing importation cost that the country has been relying on the latter source for the supply of rice. However, the fact still remains that vast potential for local cultivation of rice is established to be away from being competently exploited.

\section{Acknowledgements}

The authors thank the Harbin Institute of Technology, Harbin, China 
for supporting this research.

\section{REFERENCES}

[1] Saito, K., Sokei, Y. and Wopereis, M. (2012) Enhancing rice productivity in West Africa through genetic improvement. Crop Science, 52, 484-493. http://dx.doi.org/10.2135/cropsci2010.12.0734

[2] Touré, A., et al., (2009) Response of lowland rice to agronomic management under different hydrological regimes in an inland valley of Ivory Coast. Field Crops Research, 114, 304-310. http://dx.doi.org/10.1016/j.fcr.2009.08.015

[3] Haile, M. (2005) Weather patterns, food security and humanitarian response in Sub-Saharan Africa. Philosophical Transactions of the Royal Society B: Biological Sciences, 360, 2169-2182.

http://dx.doi.org/10.1098/rstb.2005.1746

[4] Negin, J., et al., (2009) Integrating a broader notion of food security and gender empowerment into the African Green Revolution. Food Security, 1, 351-360. http://dx.doi.org/10.1007/s12571-009-0025-z

[5] Anderson, K., Martin, W. and Valenzuela, E. (2006) The relative importance of global agricultural subsidies and market access. World Trade Review, 5, 357-376. http://dx.doi.org/10.1017/S1474745606002916

[6] Easterly, W. and Levine, R. (1997) Africa's growth tragedy: policies and ethnic divisions. The Quarterly Journal of Economics, 112, 1203-1250. http://dx.doi.org/10.1162/003355300555466

[7] Gugerty, M.K. and Gockel, R. (2009) Political economy of fertilizer, Nigeria.

[8] Sahrawat, K., Wani, S.P., Pathak, P. and Rego, T.J. (2012) Managing natural resources of watersheds in the semiarid tropics for improved soil and water quality: A review. Agricultural Water Management, 97, 375-381. http://dx.doi.org/10.1016/j.agwat.2009.10.012

[9] Sowa, N. and Kwakye, J. (1993) Inflationary trends and control in Ghana. African Economic Research Consortium Consortium pour la Recherche Economique En Afrique, Accra.

[10] Touré, K.K. and Clavel, D. (2010) Theme 1: Developing a mixed knowledge innovative system of technical, Institutional and traditional information for capacity building and empowerment of multi-stakeholders networks in Rural Africa [Article and Abstract]. Agricultural Information Worldwide, 3, 65-72.

[11] Jingzhong, Y. (2011) Left-behind children: The social price of China's economic boom. Journal of Peasant Studies, 38, 613-650.

http://dx.doi.org/10.1080/03066150.2011.582946
[12] Zhang, J., Li, X.M. Fang, X.Y. and Xiong, Q. (2009) Discrimination experience and quality of life among rural-to-urban migrants in China: The mediation effect of expectation-reality discrepancy. Quality of Life Research, 18, 291-300. http://dx.doi.org/10.1007/s11136-009-9454-6

[13] Miheretu, B.A. (2011) Causes and consequences of rural-urban migration: The case of Woldiya town, North Ethiopia. Electronic Theses and Dissertations.

[14] Reardon, T. and Timmer, C.P. (2007) Transformation of markets for agricultural output in developing countries since 1950: How has thinking changed? Handbook of agricultural economics, 3, 2807-2855.

[15] Ellis, F. (1992) Agricultural policies in developing countries. Cambridge University Press, Cambridge.

[16] Llanto, G.M. and Laviña, G.R. (2006) Innovations as response to failures in rural financial markets. Philippine Institute for Development Studies, Makati City.

[17] Sun, L., Hong, E. and Li, T. (2010) Incorporating technology diffusion, factor mobility and structural change into cro-region growth regression: An application to China. Journal of Regional Science, 50, 734-755. http://dx.doi.org/10.1111/j.1467-9787.2009.00623.x

[18] Seck, P.A., Tollens, E., Wopereis, M.C.S., Diagne, A. and Bamba, I. (2010) Rising trends and variability of rice prices: Threats and opportunities for Sub-Saharan Africa. Food Policy, 35, 403-411. http://dx.doi.org/10.1016/j.foodpol.2010.05.003

[19] Karbasi, A., et al., (2011) Applications of the policy analysis matrix in Iranian bottled drinking water factory: The case study, Sistan \& Baluchestan Region. Iran. Journal of American Science, 7, 564-570.

[20] Wen, M., Fanb, J., Jin, L. and Wang, G.X. (2010) Neighborhood effects on health among migrants and natives in Shanghai, China. Health \& Place, 16, 452. http://dx.doi.org/10.1016/j.healthplace.2009.12.001

[21] Salam, A. (2009) Distortions in incentives to production of major crops in Pakistan: 1991-2008. The Journal of International Agricultural Trade and Development, 5, 185207.

[22] Krueger, A.O., Schiff, M. and Valdés, A. (1988) Agricultural incentives in developing countries: Measuring the effect of sectoral and economywide policies. The World Bank Economic Review, 2, 255-271. http://dx.doi.org/10.1093/wber/2.3.255

[23] Ogunlade, M., Oluyole, K. and Aikpokpodion, P. (2009) An evaluation of the level of fertilizer utilization for cocoa production in Nigeria. Journal of Human Ecology, 25, 175-178. 